\title{
Irrigação do timo em aves da linhagem Paraíso Pedrês (Gallus gallus domesticus)
}

[Irrigation of thymus in Paraiso Pedres lineage (Gallus gallus domesticus) birds]

\author{
M.I. Santana ${ }^{1}$, P.P. Bombonato ${ }^{2}$, L.V. Araújo ${ }^{3,4}$, A.P.F. Castello $^{3,4}$, T.B. Escanhoela ${ }^{3}$ \\ ${ }^{1}$ Pontifica Universidade Católica \\ R. Alfredo Lopes, 76 \\ 37704-259 - Poços de Caldas, MG. \\ ${ }^{2}$ Faculdade de Medicina Veterinária e Zootecnia - USP, São Paulo, SP \\ ${ }^{3}$ Aluno de graduação - PUC - Minas - Poços de Caldas, MG \\ ${ }^{4}$ Bolsista do FIP - PUC - Minas - Poços de Caldas, MG
}

\begin{abstract}
RESUMO
A vascularização arterial do timo (número, origem e ordenação) bem como a distribuição parenquimal dos ramos penetrantes foram estudadas em 40 aves da linhagem Paraíso Pedrês. Trinta aves foram injetadas com látex e dissecadas, enquanto 10 aves tiveram seus sistemas arteriais injetados com resina (metil metacrilato e mercox) para a preparação de moldes vasculares. A principal fonte de irrigação encontrada foi a associação dos ramos oriundos das artérias comuns do nervo vago, tireóideas e ingluviais, sendo que seus ramos penetravam o parênquima dos lobos, principalmente pelas suas extremidades cranial e caudal. A partir da penetração, os ramos tímicos apresentavam distribuição predominante para a periferia do lobo, formando uma trama capilar poligonal, com espaços irregulares, característica de um órgão linforreticular.
\end{abstract}

Palavras-chave: aves, timo, vascularização, artérias

\begin{abstract}
The thymus arterial vascularization (number, origin and organization) as well as the parenchymal distribution of the penetrative branches were studied in 40 birds of Paraiso Pedres lineage birds. From this total, 30 were injected with latex and dissected, while 10 had their arterial vessels injected with resin (methylmethacrylate and mercox) for the vascular matrix preparation. The main source of irrigation found was the association of branches originated from the common arteries of the vago nerve, thyroid and ingluvial, and their branches penetrated in the parenchyma of the lobes especially through the caudal and cranial endings. From this penetration, the thymic branches showed most of their distribution to the lobe periphery, creating a polygonal capilar web with irregular, spaces which is a characteristic of a linforeticular organ.
\end{abstract}

Keywords: birds, Gallus gallus domesticus, thymus, irrigation

\section{INTRODUÇ̃̃O}

A linhagem Paraíso Pedrês, por ser um híbrido do cruzamento das linhagens Gallus bankiva, Gallus varius, Brahma, Plymouth Rock e Rhode Island, propicia um interessante estudo comparativo com as linhagens consideradas modernas (cruzamento de linhagens de galinhas silvestres como as de Sumatra, Java, Birmânia e Ceilão com o Gallus gallus, além das européias citadas anteriormente), devido principalmente à recuperação de características genotípicas que foram modificadas pelo homem, ou seja, a variação da cor da plumagem, conformação de

Recebido em 7 de julho de 2005

Aceito em 13 de dezembro de 2007

E-mail: misantana@pucpcaldas.br 
carcaça e ganho de peso. Desta forma, o estudo anatômico desta linhagem possibilita entender melhor como a hibridização modifica o padrão morfológico do timo, após maciça seleção genética imposta nos galiformes de interesse zootécnico, no último século.

Ainda, os dados obtidos poderão ser confrontados aos de outros gêneros e espécies de aves domésticas e silvestres, gerando novas fronteiras para o melhor entendimento de como ocorre o desenvolvimento e a regressão do timo nas aves (Nascimento, 2002; Santana, 2002).

Desta forma, justifica-se a realização de estudos específicos relacionados à distribuição vascular em órgãos e sistemas, principalmente no aspecto comparativo, pois, como relatado por Glenny (1945), as artérias e seus ramos, nas mais variadas ordenações, aparecem como evidência significante para a confirmação de semelhanças e relações entre diferentes grupos de animais.

Este trabalho teve o objetivo de estudar a sistemática vascular (origem, número, ordenação e distribuição parenquimal arterial) dos lobos tímicos.

\section{MATERIAL E MÉTODOS}

Utilizaram-se 40 exemplares de aves da linhagem Paraíso Pedrês (Gallus gallus domesticus), sendo 20 machos e 20 fêmeas, todas com 11 semanas de idade, doadas pela Granja Aves do Paraíso - Itatiba, SP.

Para a anestesia das aves, empregou-se o protocolo padrão sugerido por Rosskopf e Woerpel (1996), ou seja, a utilização de sobre dose de gás anestésico ${ }^{1}$, a $10 \mathrm{v} \%$, durante três minutos, valendo da sua característica de alta difusão pelo sistema respiratório das mesmas, obtendo aprofundamento do plano anestésico, com subseqüente óbito dos animais, conforme recomenda o Colégio Brasileiro de Experimentação Animal (Cobea, 2005).

Para a determinação das origens, do número e locais de penetração dos ramos destinados aos lobos tímicos, 30 aves (15 fêmeas e 15 machos)

${ }^{1}$ Halotano - Cristália Produtos Químicos e Farmacêuticos Ltda tiveram seus vasos arteriais injetados com solução aquosa de látex ${ }^{2}$ a $50 \%$ corada ${ }^{3}$, mediante canulação da artéria isquiática direita com cânula de calibre compatível. A solução foi acondicionada em seringa de plástico e injetada por meio de pressão digital constante.

Em seguida, as aves foram fixadas em solução aquosa de formol $^{4}$ a $20 \%$ e mantidas em recipientes com a mesma solução, para posterior dissecação.

Os modelos de irrigação, biometria e topografia dos lobos foram transferidos esquematicamente para fichas individuais, registrando a origem, o número e a ordenação das artérias responsáveis por sua irrigação.

Para o estudo do comportamento dos ramos arteriais no parênquima dos lobos, foram preparados moldes vasculares por corrosão, utilizando a técnica de injeção de resina acrílica auto polimerizável ${ }^{5}$ corada $^{6}$ em cinco galinhas, como descrito por Erecin et al. (1967), Sindel et al. (1990) e Aslan et al. (2000).

Para a realização da técnica de microscopia eletrônica de varredura, utilizou-se a injeção de resina acrílica modificada ${ }^{7}$ em cinco galos, seguindo a descrição de Ninomiya (2000).

A nomenclatura anatômica utilizada para designação das estruturas anatômicas tratadas neste trabalho está de acordo com a Nomina Anatomica Avium (Baumel, 1993).

Os resultados foram posteriormente tabulados e tratados estatisticamente (teste de correlação de Pearson, $\alpha=1 \%$ )

\section{RESULTADOS}

Os lobos tímicos foram observados na região cervical, desde as claviculas até as proximidades da mandíbula, em posição dorsolateral ao plexo

\footnotetext{
${ }^{2}$ Artecola $^{\circledR}$ - Altamira Indústria e Comércio de Látex

${ }^{3}$ Corante para tinta látex - Suvinil ${ }^{\circledR}$ Tintas e Pigmentos

${ }^{4}$ Chemco $^{\circledR}$ - Merse artigos para laboratórios Ltda.

${ }^{5}$ Jet X15 ${ }^{\circledR}$ (metil metacrilato) - Artigos Odontológicos Clássico

${ }^{6}$ Laca Duco Nitrocelulose - Glassurit do Brasil S/A, Indústrias de Tintas

${ }^{7}$ Mercox ${ }^{\mathrm{TM}}$ CL2-B - Japan-Vilene Company Ltd.
} 
neurovascular do pescoço, ao qual estavam envoltos por uma grossa camada de tecido adiposo e um fascículo de tecido conjuntivo, em número que variou de dois a 10 lobos para o antímero esquerdo (média de 5,53) e de três a oito lobos para o antímero direito (média de 5,40 ), não havendo diferença estatística significante para os dados correlacionados entre machos e fêmeas (Fig. 1).

Os lobos mediram, em média, $1,24 \mathrm{~cm}$ de comprimento, $0,54 \mathrm{~cm}$ de largura e $0,23 \mathrm{~cm}$ de espessura, em ambos os antímeros, não havendo diferença estatística significante para os dados correlacionados entre machos e fêmeas. Pelo tamanho avantajado, os lobos mostraram-se em íntima relação com a pele, podendo, inclusive, ser palpados externamente.

Nos antímeros contralaterais, as principais fontes de sangue para os lobos cervicais foram os ramos tímicos, ramos cutâneos, artérias tireóideas e ingluviais (Fig. 2 e 3), todos oriundos das artérias comuns do nervo vago esquerda e direita (Fig.
4). Estas, por sua vez, foram originadas respectivamente dos troncos vertebrovagais esquerdo e direito.

Especificamente, a irrigação dos lobos tímicos cervicais se deu por meio de associações vasculares, como mostram os dados abaixo: (Tab. 1 e 2)

Observou-se, em ambos os antímeros, que as artérias tireóideas craniais e caudais, ingluviais craniais e caudais, ingluvial esquerda, esofágica ascendente esquerda e ingluvial média direita originaram-se das artérias comuns do nervo vago, em todos os casos estudados, enquanto a artéria carótida comum direita era continuação direta do tronco braquiocefálico correspondente.

Diferentemente de outros órgãos parenquimatosos, não foi observada a presença de um hilo tímico, já que as ordenações das artérias participantes mostraram-se variáveis (Tab. 3 e 4 e Fig. 4).

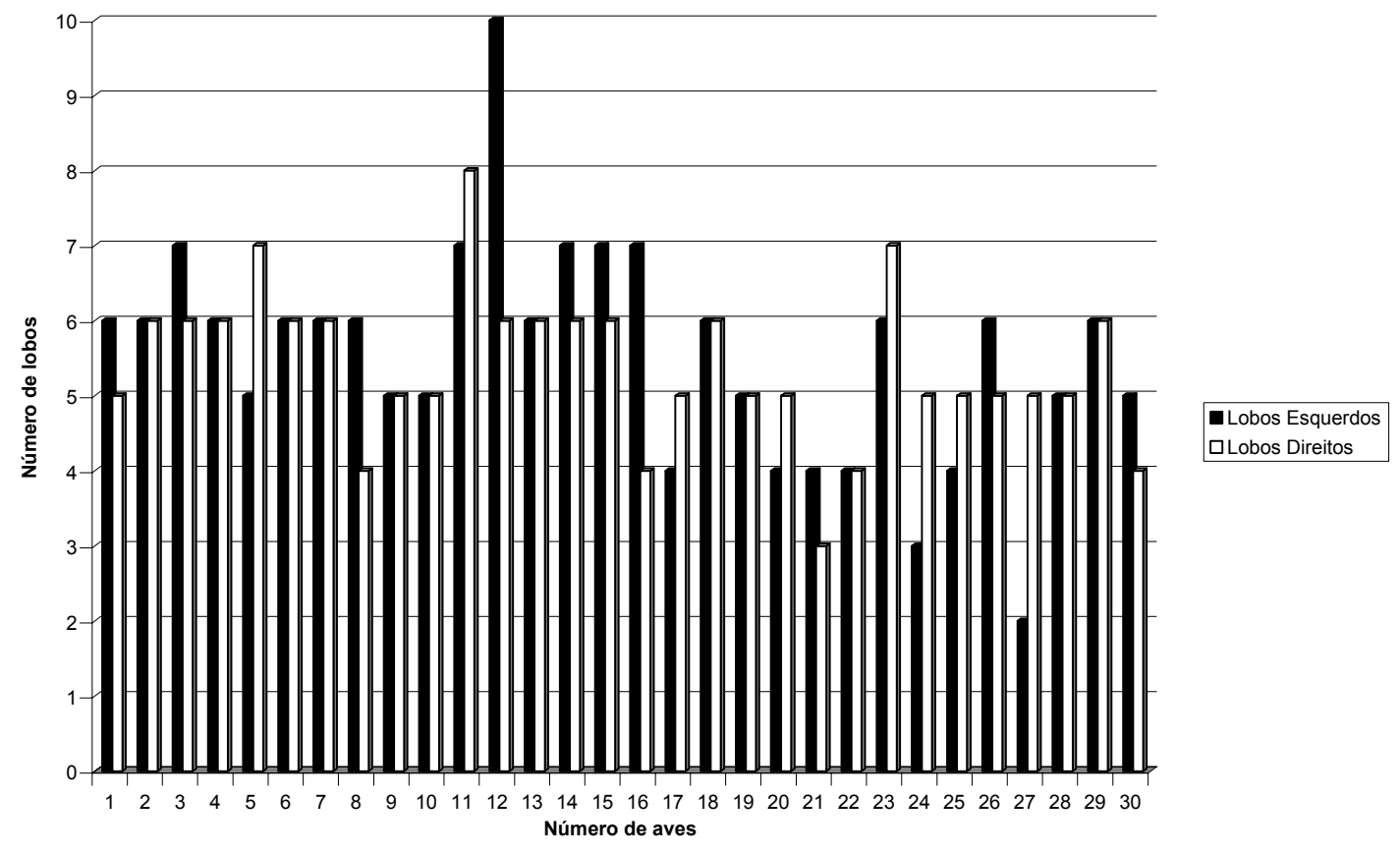

Figura 1. Distribuição dos lobos tímicos cervicais por antímero. Os números de 1 a 15 são representativos para machos e de 16 a 30 para fêmeas. 


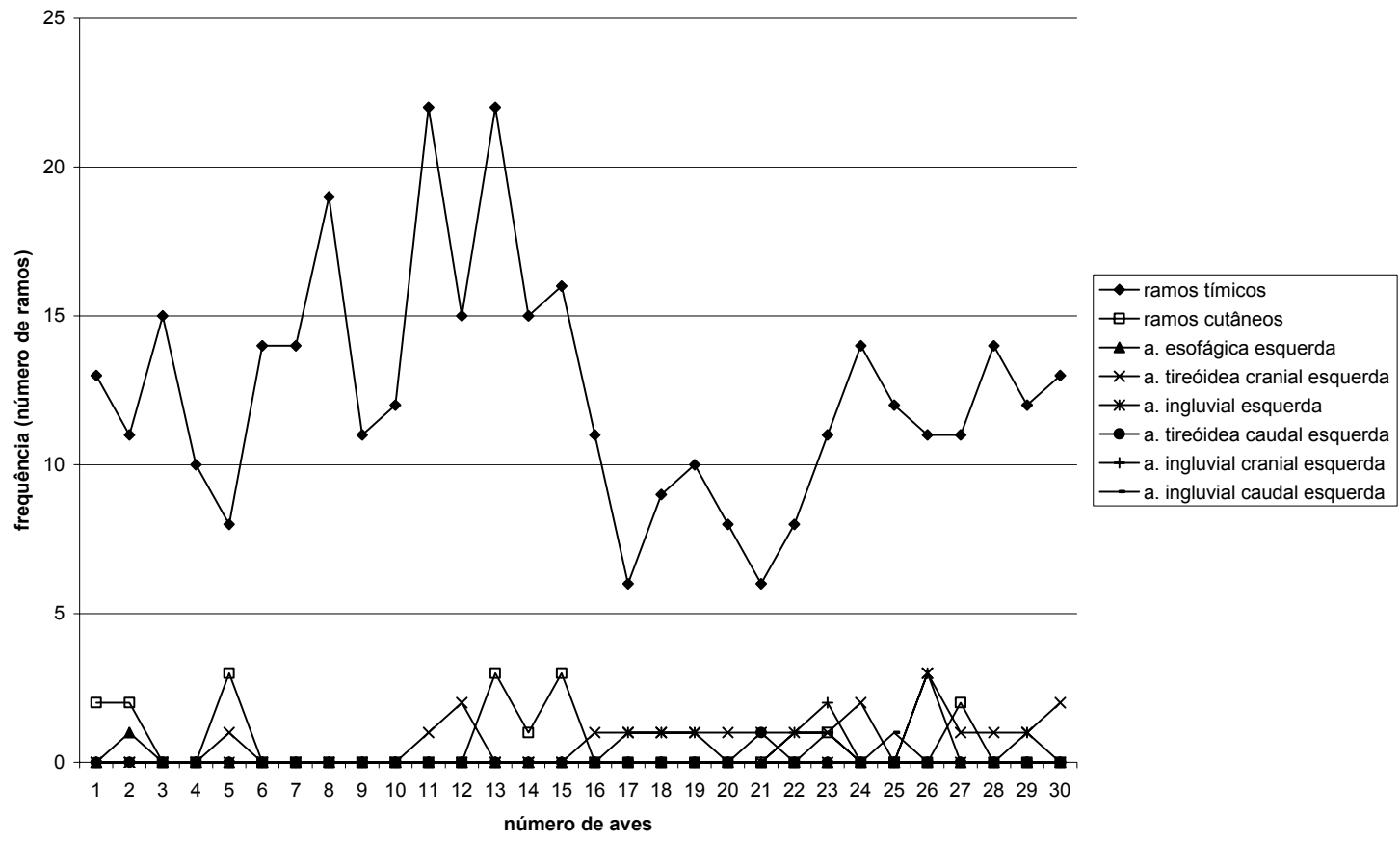

Figura 2. Distribuição dos ramos arteriais destinados aos lobos tímicos cervicais esquerdos. A freqüência foi determinada pelo número de ramos que cada artéria emitiu. Os números de 1 a 15 são representativos para machos e de 16 a 30 para fêmeas.

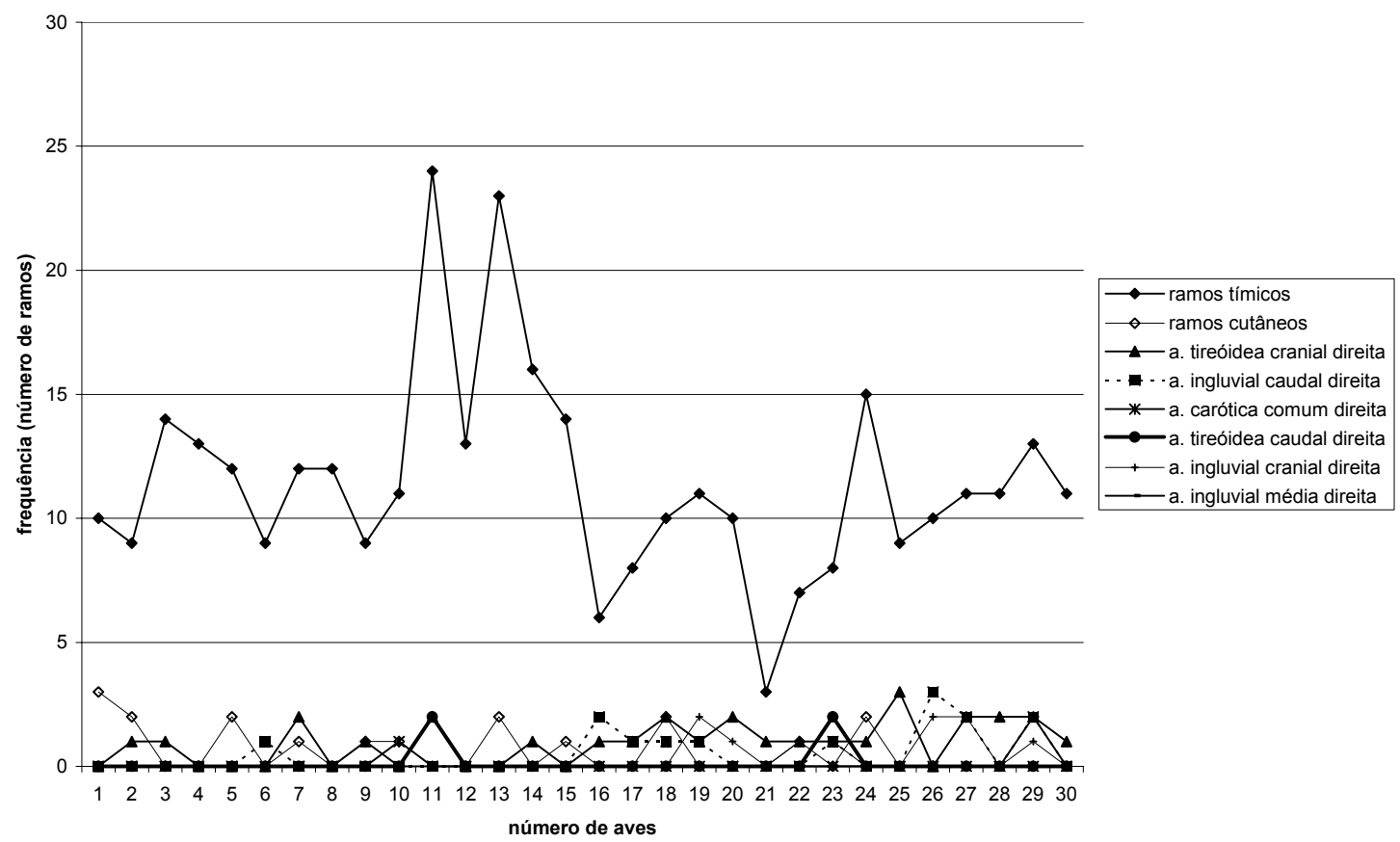

Figura 3. Distribuição dos ramos arteriais destinados aos lobos tímicos cervicais direitos. A freqüência foi determinada pelo número de ramos que cada artéria emitiu. Os números de 1 a 15 são representativos para machos e de 16 a 30 para fêmeas. 
Irrigação do timo em aves da linhagem...

Tabela 1. Associações vasculares responsáveis pela irrigação dos lobos tímicos cervicais esquerdos. Os ramos e artérias participantes foram originados no antímero esquerdo

\begin{tabular}{lcc}
\hline Associação vascular & Número de casos Freqüência \\
\hline Ramos tímicos & 7 & $23,3 \%$ \\
Ramos tímicos, a. tireóidea cranial & 7 & $23,3 \%$ \\
Ramos tímicos, a. tireóidea cranial, a. ingluvial & 5 & $16,6 \%$ \\
Ramos tímicos, ramos cutâneos & 4 & $13,3 \%$ \\
Ramos tímicos, ramos cutâneos, a. tireóidea cranial & 2 & $6,6 \%$ \\
Ramos tímicos, ramos cutâneos, a. esofágica ascendente & 1 & $3,3 \%$ \\
Ramos tímicos, a. tireóidea cranial, a. tireóidea caudal & 1 & $3,3 \%$ \\
Ramos tímicos, a. tireóidea cranial, a. ingluvial cranial, a. ingluvial caudal & 1 & $3,3 \%$ \\
Ramos tímicos, ramos cutâneos, a. tireóidea cranial, a. ingluvial cranial, a. & 1 & $3,3 \%$ \\
ingluvial caudal & 1 & $3,3 \%$ \\
Ramos tímicos, a. ingluvial caudal & 1 & \\
\hline
\end{tabular}

Tabela 2. Associações vasculares responsáveis pela irrigação dos lobos tímicos cervicais direitos. Os ramos e artérias participantes foram originados no antímero direito

\begin{tabular}{lcc}
\hline Associação vascular & $\begin{array}{c}\text { Número de } \\
\text { casos }\end{array}$ & Freqüência \\
\hline Ramos tímicos, ramos cutâneos & 5 & $16,6 \%$ \\
Ramos tímicos, a. tireóidea cranial & 5 & $16,6 \%$ \\
Ramos tímicos, ramos cutâneos, a. tireóidea cranial & 4 & $13,3 \%$ \\
Ramos tímicos & 3 & $13,3 \%$ \\
Ramos tímicos, a. tireóidea cranial, a. tireóidea caudal & 3 & $13,3 \%$ \\
Ramos tímicos, a. ingluvial caudal & 2 & $6,6 \%$ \\
Ramos tímicos, ramos cutâneos, a. carótida comum & 1 & $3,3 \%$ \\
Ramos tímicos, ramos cutâneos, a. tireóidea cranial, a. ingluvial caudal & 1 & $3,3 \%$ \\
Ramos tímicos, a. tireóidea cranial, a. ingluvial cranial, a. ingluvial caudal & 1 & $3,3 \%$ \\
Ramos tímicos, a. tireóidea cranial, a. ingluvial cranial & 1 & $3,3 \%$ \\
Ramos tímicos, ramos cutâneos, a. tireóidea cranial, a. ingluvial cranial & 1 & $3,3 \%$ \\
Ramos tímicos, a. tireóidea cranial, a. ingluvial cranial, a. tireóidea caudal, a. & 1 & $3,3 \%$ \\
ingluvial caudal & 1 & $3,3 \%$ \\
Ramos tímicos, a. ingluvial cranial, a. ingluvial caudal & 1 & $3,3 \%$ \\
Ramos tímicos, a. tireóidea cranial, a. ingluvial caudal, a. ingluvial cranial & & \\
\hline
\end{tabular}

Tabela 3. Diferentes locais de penetração dos ramos participantes da irrigação dos lobos tímicos cervicais esquerdos

\begin{tabular}{lc}
\hline Local de Penetração & Freqüência \\
\hline Extremidades cranial e caudal & $41,0 \%$ \\
Terço médio e extremidades cranial e caudal & $24,1 \%$ \\
Terço médio & $21,1 \%$ \\
Extremidade cranial & $5,4 \%$ \\
Extremidade cranial e terço médio & $3,0 \%$ \\
Extremidade caudal e terço médio & $3,0 \%$ \\
Extremidade caudal & $2,4 \%$ \\
\hline
\end{tabular}

Tabela 4. Diferentes locais de penetração dos ramos participantes da irrigação dos lobos tímicos cervicais direitos

\begin{tabular}{lc}
\hline Local de Penetração & Freqüência \\
\hline Extremidades cranial e caudal & $42,6 \%$ \\
Terço médio & $27,4 \%$ \\
Extremidades cranial e caudal e terço médio & $16,0 \%$ \\
Extremidade cranial e terço médio & $5,5 \%$ \\
Extremidade cranial & $4,9 \%$ \\
Extremidade caudal e terço médio & $2,4 \%$ \\
Extremidade caudal & $1,2 \%$ \\
\hline
\end{tabular}


Predominantemente, os ramos participantes da irrigação dos lobos emergiram pela face lateral do vaso principal, indo de acordo com a topografia do lobo. No entanto, quando observados os ângulos de penetração dos mesmos, ficou patente que a maioria $(59,2 \%$ dos ramos) estava por volta dos $45^{\circ}$ em relação à artéria de origem, enquanto nos restantes, o ângulo estava por volta de $30^{\circ}(28,5 \%$ dos ramos) e $90^{\circ}(12,3 \%$ dos ramos). Além do mais, estes poderiam estar em ângulo agudo (71,9\% dos ramos), obtuso $(11,9 \%$ dos ramos) ou reto $(16,2 \%$ dos ramos).

Quando da observação dos moldes preparados em resina acrílica autopolimerizável, obteve-se que em $75 \%$ deles (Fig. 5), os ramos, ao penetrarem no parênquima lobar, mostraram trajeto quase retilíneo (38\% dos moldes) ou ligeiramente encurvado (62\% dos moldes), emitindo ramos em faces alternadas, (lateralmente, medialmente, dorsalmente e ventralmente), num curto intervalo. Estes ramos, por sua vez, emitiram colaterais menores direcionados para a periferia do lobo. Em 25\% dos moldes, logo no ponto de penetração, o ramo se dividia em três ou quatro ramos direcionados medialmente, dos quais partiam outros menores para a periferia. Dessa forma, observou-se um padrão predominantemente medular para os vasos principais e cortical para seus colaterais.

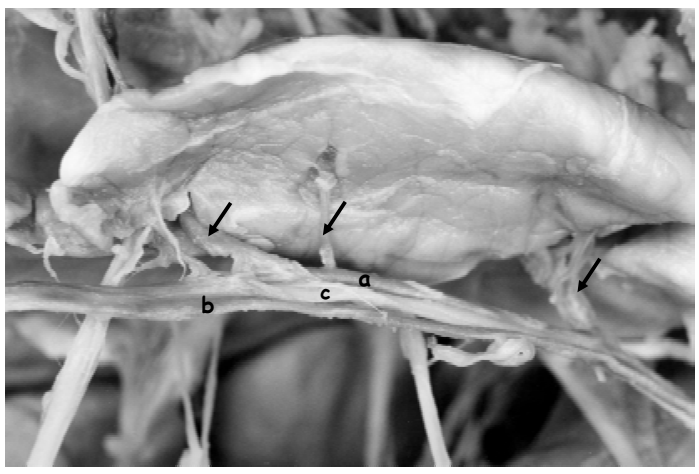

Figura 4. Macrofotografia de um lobo tímico mostrando a relação dorsolateral com o plexo neurovascular do pescoço, além dos pontos de penetração cranial, médio e caudal dos ramos tímicos (setas). Artéria comum do nervo vago (a), veja jugular (b) e nervo vago (c). Fator de Ampliação 3:1.

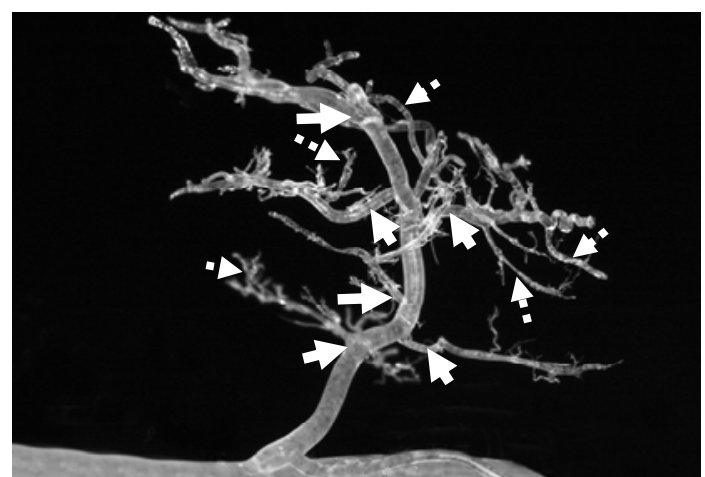

Figura 5. Macrofotografia de um molde arterial de metil metacrilato, oriundo da artéria ingluvial caudal direita, mostrando seu ângulo agudo de saída, com aproximadamente de $45^{\circ}$ (seta branca maior, encurvado $(*)$ e emitindo ramos em faces alternadas (setas brancas do lobo (setas tracejadas). Fator de Ampliação 4:1.

Já a leitura dos moldes arteriais feitos em $\operatorname{Mercox}^{\mathrm{TM}}$ pela técnica de miscroscopia eletrônica de varredura, da mesma forma que os anteriores, permitiu verificar a ausência de anastomoses entre ramos centrais ou periféricos pertencentes ao mesmo ou a outro lobo adjacente, deixando extremamente clara a disposição central do ramo principal, que foi responsável pela origem de um número variado de colaterais direcionados para a periferia do órgão. Destes últimos, emergiram diversos outros ramos menores e ainda mais periféricos, os quais foram formadores de uma rede poligonal, com espaços de tamanhos e formas irregulares, além de lóbulos tímicos totalmente individualizados (Fig. 6).

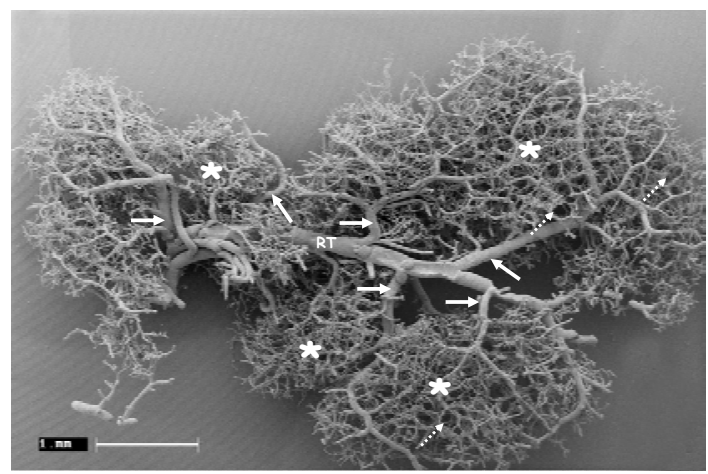

Figura 6. Fotomicrografia eletrônica de varredura de lobo tímico mostrando a imagem arboriforme do órgão com seus lóbulos tímicos distintos (asteriscos), formados por redes capilares corticais. Ramo tímico medular (seta pontilhada) e seus colaterais direcionados à região cortical (setas cheias), formando uma rede de espaços poligonais (setas tracejadas). 
Ainda, quando correlacionados o número de lobos x número de ramos arteriais, obtiveram-se correlações positivas de média intensidade, significando que existe uma forte tendência para quanto maior o número de lobos, mais ramos chegarão ao seu parênquima. Porém, quando se correlaciona posição $\mathrm{x}$ tamanho $\mathrm{x}$ irrigação dos lobos, obtiveram-se correlações positivas de baixa intensidade, demonstrando não existir correlação entre estes aspectos.

\section{DISCUSSÃO}

No referente à origem dos vasos arteriais responsáveis pela irrigação do timo, pode-se notar que as aves Paraíso Pedrês mostraram um arranjo peculiar quando confrontados com outras linhagens avícolas, pois demonstram aquilo que seria esperado para todas as aves, ou seja, a predominante participação dos ramos tímicos oriundos da artéria comum do nervo vago, pois é o vaso que apresenta relação direta com os lobos, principalmente por estarem unidos por um fascículo de tecido conjuntivo (Baumel, 1964). Porém, quando comparadas com outros galiformes, notou-se ser este um padrão característico desta linhagem, já que relatos constantes de Santana et al. (2000), Santana et al. (2001), Nascimento (2002) e Santana (2002) revelaram um número superior de associações arteriais, principalmente no que se refere às artérias tireóideas, ingluviais e esofágicas, além de outras que não foram observadas neste trabalho, como as artérias carótida interna, subclávia e supraescapulares e comumente encontradas para outros galiformes (Santana et al., 2000; Santana et al., 2001; Santana, 2002).

Talvez isso possa ser explicado pelo tamanho avantajado dos lobos tímicos dissecados, sendo que a intimidade das artérias comuns do nervo vago com os lobos represente uma vantagem, pois a proximidade pode propiciar um melhor fluxo sangüíneo nos ramos destinados aos lobos. Isso também tem a ver com a angulação dos ramos próxima aos $45^{\circ}$, pois Nicoll e Webb (1954) postularam que essa angulação ajuda a uniformizar a distribuição de sangue e a pressão dentro do ramo direto, favorecendo, dessa forma, um fluxo quase que constante no parênquima.

Por outro lado, a presença de grande quantidade de tecido adiposo na região cervical é um fator determinante para o baixo número de associações vasculares encontradas, pois, de acordo com os relatos de Santana et al. (2000), Santana et al. (2001), Nascimento (2002) e Santana et al. (2002), foram encontradas relações diretas dos lobos tímicos dispostos no terço caudal do pescoço com artérias adjacentes que apresentavam área de irrigação nesta região. Estas características eram possíveis porque os lobos estavam envoltos apenas pelos sacos aéreos claviculares e uma delgada camada de tecido adiposo.

Com relação aos ramos penetrantes, não ficou evidente a presença de um hilo tímico (Pereira, 1998; Santana et al., 2000; Santana et al., 2001), já que os ramos diretos mostraram pontos variáveis de penetração no parênquima lobar. Porém, essa característica em nada influencia a arquitetura vascular lobar, demonstrando que este é um fator de menor importância dentro da vascularização do órgão.

Relativamente à angioarquitetura lobar, deve-se levar em consideração que tanto os moldes feitos em resina autopolimerizável como os de Mercox $^{\mathrm{TM}}$ mostraram características muito semelhantes para a distribuição parenquimal, ou seja, a ramificação ordenada do centro para a periferia dos lobos tímicos, formando uma extensa rede capilar cortical. No entanto, este arranjo pode ser considerado padrão para os galiformes (Scala et al., 1981), apesar de pequenas modificações encontradas para a galinha da angola, em que a ramificação também foi centroperiférica, mas a partir dos ramos mais exíguos (Santana, 2002).

Além disso, a predominância periférica dos capilares nos lobos mostrou a necessidade de um fluxo sangüíneo uniforme e contínuo, pois sendo um órgão linfóide primário, o movimento dos linfócitos por meio de vênulas pós-capilares deve ser constante (Nicoll e Webb, 1954), justificando, assim, o grande número de capilares corticais.

\section{CONCLUSÕES}

Por meio das associações vasculares e tamanho dos lobos cervicais, ficou estabelecido que a irrigação parenquimal segue uma proporção, quanto maior o número de lobos, maior será o 
número de ramos arteriais emitidos. A partir disso, pode-se criar um modelo de distribuição arterial, formado principalmente pelas artérias comuns do nervo vago, tireóidea e ingluvial. Ainda, a ordenação dos ramos arteriais permitiu fazer uma analogia com outros órgãos linforreticulares, pois a região cortical dos lobos mostrou-se povoada por números capilares e vênulas, enquanto a região medular é pouco vascularizada, representando, portanto, o ponto de divisão dos ramos penetrantes.

\section{REFERÊNCIAS BIBLIOGRÁFICAS}

ASLAN, K.; OZCAN, S.; KURTUL, I. Arterial vascularization of the uripygial glands in geese (Anser anser) and ducks (Anas platyrhynches), Anat. Histol. Embryol., v.29, p.291-293, 2000.

BAUMEL, J.J. Handbook of avian anatomy: nomina anatomica avium. 2.ed. Cambridge: Nuttall Ornithological Club, 1993. 779p.

BAUMEL, J.J. Vertebral-dorsal carotid artery interrelationships in the pigeon and other birds. Anat. Anz., v.114, p.113-130, 1964.

COBEA. Legislação e ética. Princípios éticos na experimentação animal. Disponível em $<$ http://www.cobea.org.br/ética $>$. Acessado em 5 abr. 2005 .

ERECIN, Z. HASSA, A.; SAGLAM, M. et al., A. Development of plastic demonstration methods for vessel and canal system by injection. J. Fac. Vet. Med. Ankara Univ., v.14, p.444-459, 1967.

GLENNY, F.H. A systematic study of the main arteries in the region of the heart. Aves XXI. Ohio J. Sci., v.155, p.19-21, 1945.

NASCIMENTO, M.A. Vascularização arterial do timo em aves (Gallus gallus domesticus, Linnaeus, 1758) da linhagem Cobb. 2002. 91f. Dissertação (Mestrado) - Faculdade de Medicina
Veterinária e Zootecnia, Universidade de São Paulo, São Paulo.

NICOLL, P.A.; WEBB, R.L. The bat wing as a subject for studies in homeostasis of capillary beds. Anat. Rec., v.120, p.253-263, 1954.

NINOMIYA, H. The vascular bed in the rabbit ear: microangiography and scanning electron microscopy of vascular corrosion casts. Anat. Histol. Embryol., v.29, p.301-305, 2000.

PEREIRA, C.C.H. Irrigação arterial do timo em aves (Gallus gallus domesticus) da linhagem Hubbard. 1998. 72f. Dissertação (Mestrado) Faculdade de Medicina Veterinária e Zootecnia, Universidade de São Paulo, São Paulo.

ROSSKOPF, W.; WOERPEL, R. Diseases of cage and aviary birds. 3.ed. New York : Willians \& Nilkins, 1996. p.84-86.

SANTANA, M.I.S. Morfologia e vascularização arterial do timo em galinhas da angola (Numidea meleagris galeata). 2002. 137f. Tese (Doutorado) - Faculdade de Medicina Veterinária, Universidade de São Paulo, São Paulo.

SANTANA, M.I.S.; SILVA, F.O.C., SEVERINO, R.S. et al. Vascularização arterial do timo em aves (Gallus gallus domesticus) da linhagem Avian Farms. Biosc. J., v.16, p.3-15, 2000.

SANTANA, M.I.S.; SILVA, F.O.C., SEVERINO, R.S. et al. Vascularização arterial do timo em aves (Gallus gallus domesticus Linnaeus, 1758) da linhagem NPK. Vet. Not., v.7, 13-19, 2001.

SCALA, G.; BUDETTA, G.; COLELLA, G. Sulla microvascularizzazione del timo nel uccelli: ricerche in Gallus gallus. Boll. Soc. Ital. Biol. Sperim., v.57, p.272-274, 1981.

SINDEL, M.; UCAR, Y.; OZCAN, O. Renal arterial system of the domestic rabbit (Oryctolagus cuniculus) corrosion casts study. $J$. Anat. Soc. India, v.39, p.31-40, 1990. 